\title{
Impact of olokizumab on platelets, leukocytes and erythrocytes during mild COVID-19
}

\author{
Liudmila Buryachkovskaya ${ }^{1}$, Nikita Lomakin ${ }^{2}$, Arthur Melkumyants ${ }^{1,3}$, Julia Docenko ${ }^{1}$, Victor Serebruany ${ }^{4, *}$ \\ ${ }^{1}$ National Cardiology Research Center, 121552 Moscow, Russia \\ ${ }^{2}$ Cardiology Division, Central Clinical Hospital of Presidential Administration, 121359 Moscow, Russia \\ ${ }^{3}$ Institute of Physics and Technology, 141701 Moscow, Russia \\ ${ }^{4}$ Neurology, Johns Hopkins University, Baltimore, MD 21794, USA \\ *Correspondence: vserebr1@jhmi.edu; heartdrug@aol.com (Victor Serebruany)
}

DOI:10.31083/j.rcm2203065

This is an open access article under the CC BY 4.0 license (https://creativecommons.org/licenses/by/4.0/).

Submitted: 31 August 2021 Revised: 2 September 2021 Accepted: 8 September $2021 \quad$ Published: 24 September 2021

Numerous approaches have been tested to combat the ongoing COVID-19 pandemic targeting interleukin-6 (IL6) blockade. Since IL-6 targeting represents a cornerstone to prevent systemic inflammation various existing agents including array of monoclonal antibodies $(\mathrm{mAb})$ are in search for COVID-19 indication approval [1]. Olokizumab (Artlegia ${ }^{\circledR}$; UCB Pharma, Brussels, Belgium), an anti-IL-6 humanized IgG4k mAb blocking the interaction with the signaling co-receptor gp130 [2]. The drug is now in late-stage studies combating rheumatoid arthritis, Crohn's disease, neurodegenerative disorders and being tested for COVID-19 indication including newly hospitalized patients, addition to standard therapy, or preventing emergent cytokine storm complications. Since COVID-19 may cause disbalances in cell-endothelial interactions, the blood cells characterization seems important. Obviously, the life-threatening COVID19 presentations are associated with thrombophilia including disseminated intravascular coagulopathy especially in fatal cases $[3,4]$. Nevertheless, the proof of such link should not be documented by small sample size clinical observations or autopsy data, while direct cellular data in survivors, or the impact of anti-IL-6 agents on blood cell preservation and endothelial dysfunction are not clear. Our data reflect scanning electron microscopy findings after olokizumab on erythrocytes, leukocytes, and platelets in mild COVID-19 patients in the hospital setting. Admitted patients $(n=33)$ with PCRconfirmed COVID-19 diagnosis stated the clinic from May 25 to July 22, 2020 and included in this single-center prospective observational project. The details are outlined elsewhere [5].

Since the half-life of olokizumab is over 30 days, patients $(\mathrm{n}=13)$ received a single $64 \mathrm{mg}$ subcutaneous injection, and compared with COVID-19 positive matched controls ( $\mathrm{n}=$ 20) treated without olokizumab. Two venous blood samples (admission and discharge) were collected for electron microscopy. The demographic variables and comorbid conditions in the COVID-19 patients match well, but not perfectly since the sample size was small. All patients survived over the hospital stay with no patient was transferred to intensive care unit or required mechanical ventilation support.

The changes in blood cell structures before and after olokizumab are exhibited in Fig. 1. Obviously, any definite considerations will be inappropriate here especially considering small groups, polypharmacy, and unclear clinical significance of the index findings. Moreover, our COVID negative controls and those treated without olokizumab were not ideally matched with the experimental group. Obviously, more detailed methodology beyond electron microscopy should apply to determine true impact of the drug on COVID-damaged bleed cells. Nevertheless, few meaningful issues are worth mentioning here. It seems, the IL-6 inhibition positively affects red cell membrane permeability, diminishing echinocytosis and sludged pile formation. These data suggest that olokizumab exhibits similar effect as tocilizumab [5] in diminishing leukocyte but not platelet activation. However, in contrast to tocilizumab [5], the impact of olokizumab on platelet activity seems to be dependent on the enoxaparin dose. In short, there is no signal that olokizumab cause negative changes in blood cell structure during COVID, however, the potency of tocilizumab-related cellular effects were more profound [6]. Also alarming is the finding that even mild COVID is associated with residual deterioration of major blood cells indicative of ongoing damage after acute phase of disease. Comparative studies among IL-6 inhibitors are required to identify the best anti-inflammatory strategies in COVID survivors. The long-term blood cell damage should be considered for such trials with regard to biomarker endpoints and length of follow-up. 


\section{COVID-19 patients}
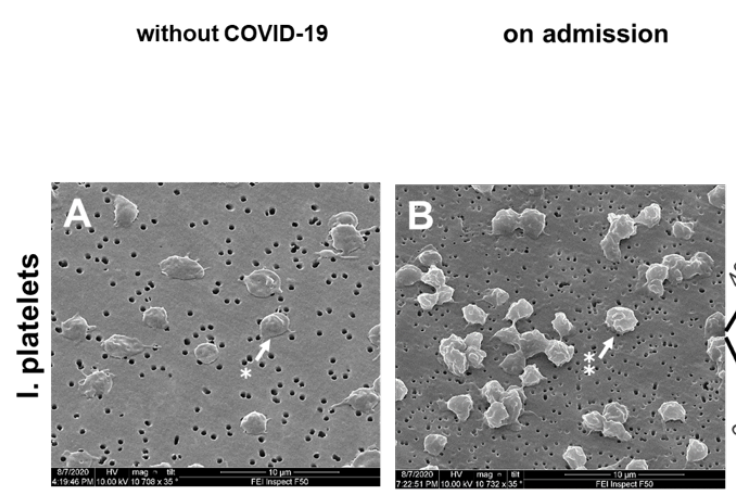

on discharge olokizumab

on discharge without therapy olokizumab therapy
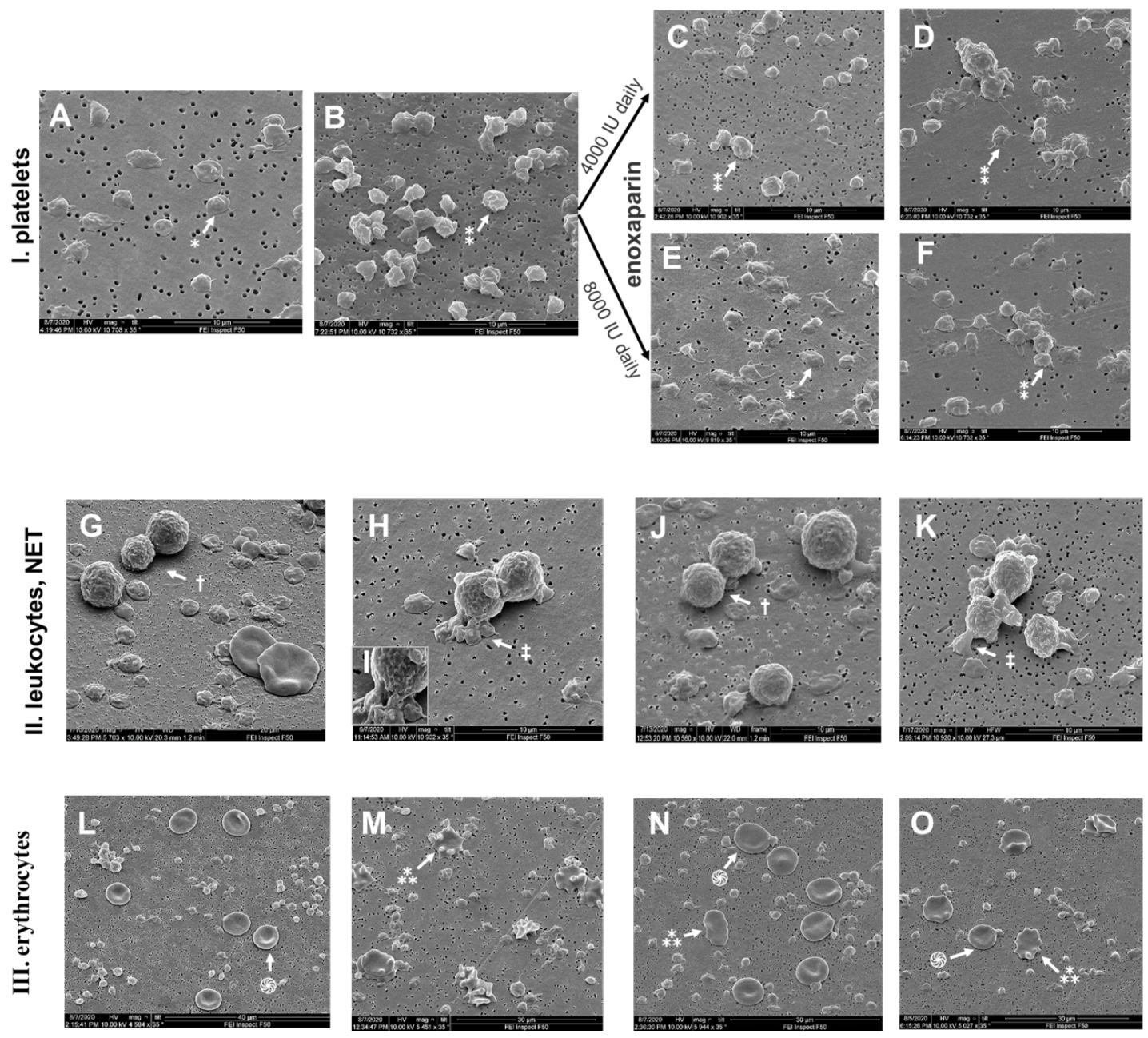

Fig. 1. Effect of olokizumab on blood cell phenotypes in COVID-19 patients.

I. Platelets. Mostly discs in controls (A); less quantity, activation, sphere transformation, at COVID-19 admission (B); Olokizumab effect on platelets is dependent on enoxaparin dose. Daily enoxaparin $4000 \mathrm{IU}$ on top of Mab cause no effect, but enoxaparin $8000 \mathrm{IU}+$ olokizumab decrease platelet activation (E) more than basic therapy without MAb (F). Arrows indicate normal discoid platelets $\left(^{*}\right)$ and activated spherical platelets (*). Magnification $\times 10,000$ for all cell images.

II. Leukocytes. No clusters or neutrophil extracellular traps in controls (G); massive traps in COVID admission samples exhibited by N-arrows (H); less or no traps after olokizumab $(\mathrm{J})$, and more traps without $\mathrm{Mab}(\mathrm{K})$. Arrows indicate single neutrophils $(\dagger)$ and neutrophil extracellular traps $(\ddagger)$. Magnification $\times$ 10,000 for all cell images.

III. Erythrocytes. Biconcave shape with no rouleaux formation in controls (L); transformation of erythrocytes into echinocytes (M); less echinocytes in

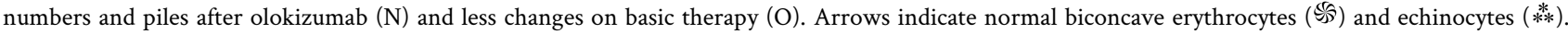
Magnification $\times 5000$ for all cell images.

\section{Author contributions}

VS has full access to all study data and takes responsibility for the integrity of the data and the accuracy of the data analysis. Concept and design-LB, NL and VS. Acquisition, analysis, or interpretation of data-All authors. Drafting of the manuscript-LB Critical revision for important intellectual content-VS. Statistical analysis-LB, JD. Obtained fundingAM, VS. Patients chart review-JD. Supervision-VS.

\section{Ethics approval and consent to participate}

Not applicable.

\section{Acknowledgment}

We are indebted to Dr. Vyacheslav Golkov (Nanopromimport, Science Park in Moscow State University) and engineer Igor Bogdanov for excellent technical support. We are grateful to the research nurse Irina 
Varyushkina for patient data collection. The study was supported by the Russian Foundation for Basic Research (grant No. 19-015-00213) to Dr. Melkumyants and unrestricted grant from HeartDrug ${ }^{T M}$ Research LLC (Wilmington, Delaware, USA) to Dr. Serebruany.

\section{Funding}

The study was supported by the Russian Foundation for Basic Research (grant No. 19-015-00213) to Dr. Melkumyants and unrestricted grant from HeartDrug ${ }^{T M}$ Research LLC (Wilmington, Delaware, USA) to Dr. Serebruany. The funders were not involved in the design and conduct of the study; collection, management, analysis, and interpretation of the data; preparation, review, or approval of the manuscript; and decision to submit the manuscript for publication by way of individuals employed by the funding institution who are included as authors or in the acknowledgments.

\section{Conflict of in terest}

The authors declare no conflict of interest.

\section{References}

[1] Kaplon H, Reichert JM. Antibodies to watch in 2021. MAbs. 2021; 13: e1860476.

[2] Shaw S, Bourne T, Meier C, Carrington B, Gelinas R, Henry A, et al. Discovery and characterization of olokizumab. MAbs. 2014; 6: 773-781.

[3] Connors JM, Levy JH. Thromboinflammation and the hypercoagulability of COVID-19. Journal of Thrombosis and Haemostasis. 2020; 18: 1559-1561.

[4] O’Sullivan JM, Gonagle DM, Ward SE, Preston RJS, O’Donnell JS. Endothelial cells orchestrate COVID-19 coagulopathy. The Lancet Haematology. 2020; 7: e553-e555.

[5] Melkumyants A, Buryachkovskaya L, Lomakin N, Antonova O, Serebruany V. Mild COVID-19 and Impaired Blood CellEndothelial Crosstalk: Considering Long-Term Use of Antithrombotics? Thromb Haemost. 2021. (in press)

[6] Buryachkovskaya L, Lomakin N, Melkumyants A, Docenko J, Serebruany V. Tocilizumab, blood cells and mild COVID-19: Delayed vascular protection by interleukin blockade? European Heart Journal - Cardiovascular Pharmacotherapy. 2021. (in press) 